\title{
The plant growth promoting bacterium Bacillus sp. CaSUT007 produces phytohormone and extracellular proteins for enhanced growth of cassava
}

\author{
Natthiya Buensanteai ${ }^{1,2^{*}}$, Mathukorn Sompong ${ }^{1}$, Kanjana Thamnu ${ }^{3}$, Dusit Athinuwat ${ }^{4}$, \\ Alain Brauman ${ }^{2}$ and Claude Plassard ${ }^{2}$
}

${ }^{1}$ School of Crop Production Technology, Institute of Agriculture Technology, Suranaree University of Technology, Nakhon Ratchasima, 30000 Thailand.

${ }^{2}$ Unité Mixte de Recherche Eco\&Sols (Ecologie fonctionnelle \& biogéochimie des Sols \&des Agroécosystèmes), UMR 1222 INRA-IRD-SupAgro Montpellier, Place Pierre Viala, 34060 Montpellier cedex 01, France.

${ }^{3}$ Synchrotron Light Research Institute (public organization), Ministry of Science and Technology of the Royal Thai Government, Muang, 30000 Nakhonratchasima, Thailand.

${ }^{4}$ Major of Organic Farming Management, Faculty of Science and Technology, Thammasat University, Pathumthani, 12121, Thailand.

Accepted 3 May, 2013

\begin{abstract}
Bacillus sp. strain CaSUT007, a plant growth promoting rhizobacterium isolated from cassava, was investigated for the secretion of compounds that might be involved in plant growth promotion. Extracts containing phytohormone and extracellular proteins were made from the cell-free fluid of CaSUT007 broth cultures. These extracts, along with a whole culture of CaSUT007 and the raw fluid and cellular fractions from a CaSUT007 culture, were applied separately to cassava stakes. The stakes were planted into pots of soil maintained in a greenhouse condition. Under this condition, all of the extracts including phytohormones and extracellular proteins increased root and shoot lengths and cassava biomass as compared to negative control. Our results indicate that the culture extracts, when applied to cassava stakes, increased root and shoot lengths by more than $30 \%$, and increased fresh and dry weights by more than $25 \%$ compared to the distilled water control. Thus, photohormone and extracellular proteins secreted by CaSUT007 can influence plant growth and development. Analysis of the photohormone and extracellular proteins extracts revealed indole-3-acetic acid and peptides to be the primary compounds.
\end{abstract}

Key words: Cassava, growth promotion, Bacillus, extracellular proteins, phytohormone.

INTRODUCTION

Bacillus sp. CaSUT007, a strain of plant growth promoting rhizobacteria (PGPR) isolated from a cassava farmer field in northeast of Thailand, can enhance growth promotion of cassava crop and inhibit the fungal pathogens causal agent of cassava diseases (Buensanteai et al., 2011). When applied as a cassava stakes treatment, it can also promote the growth of cassava (Buensanteai et al., 2011). The mechanisms by which CaSUT007 promotes plant growth are not well understood.

In addition to CaSUT007, strains classified in genus Bacillus sp. have been reported to be effective for the 
biocontrol of phytopathogens and for plant growth promotion (Araujo et al., 2005; Kloepper et al.,2004; Idriss et al., 2002; Buensanteai et al., 2011). Extrapolating from the accumulative literature on these species and on other species of PGPR, numerous mechanisms are possible in CaSUT007: as antagonist against pathogens, alteration of nutrient availability and direct interactions with plants. All of these interactions could potentially lead to plant growth promotion (Buensanteai et al., 2011).

As a starting point towards understanding how CaSUT007 causes enhanced plant growth, we focused this study on factors secreted by CaSUT007 that might directly affect the physiology of cassava plants. In this context, the production of auxins, indolic compounds with phytohormone activity, by Bacillus spp. is well known (Araujo et al., 2005; Kloepper et al., 2004; Idriss et al., 2002; Buensanteai et al., 2008). Indole-3-acetic acid (IAA), the main auxin in plants, controls important processes including cell enlargement and division and tissue differentiation. Regulation of these processes requires a balance between auxins and other phytohormones. Thus, IAA production by strains of PGPR can contribute sufficient auxin to the plant's auxin pool to have profound effects on these processes and potentially allow the microorganisms to redirect a plant's physiology and biochemistry for their own benefit (Idriss et al., 2002; Leveau and Lindow, 2005; Patten and Glick, 2002; Buensanteai et al., 2011).

Another large group of bacteria-secreted compounds is extracellular proteins. Strains in the Bacillus group secrete high levels of extracellular proteins as enzymes and secondary metabolites (Buensanteai et al., 2008). Some proteins secreted by Bacillus spp. are involved in key ecological functions such as biofilm formation (Buensanteai et al., 2008), but extracellular proteins, as a group, have not yet been investigated in the context of plant growth promotion.

The mechanisms of CaSUT007 promotion of plant growth are not well understood. Then, the goal of this study was to determine whether or not compounds secreted by CaSUT007 have a direct role in regulating plant growth, which promotes plant growth under control conditions. One objective was to determine whether indoles and extracellular proteins produced by CaSUT007 in liquid culture could enhance growth of cassava when applied to cassava stakes. Another objective was to analyze the extracellular proteins and phytohormone extracts from CaSUT007 to identify the primary components.

\section{MATERIALS AND METHODS}

\section{Culture conditions and preparation of extracellular extracts}

Cells of Bacillus sp. strain CaSUT007 stored in nutrient glucose broth with $10 \%$ glycerol at $-80^{\circ} \mathrm{C}$ were revived by streaking onto nutrient glucose agar (NGA) and cultured at $28 \pm 2{ }^{\circ} \mathrm{C}$ for $48 \mathrm{~h}$. To prepare cultures for extraction of extracellular factors, the strain was transferred to $500 \mathrm{~mL}$ volumes of nutrient broth containing $2 \%$ glucose (NGB) and incubated for $48 \mathrm{~h}$ at $28 \pm 2^{\circ} \mathrm{C}$ with constant shaking at $180 \mathrm{rpm}$. The cultures were centrifuged at $13,000 \mathrm{rpm}$ at $4^{\circ} \mathrm{C}$ for $20 \mathrm{~min}$ and the supernatants were passed through $0.2 \mathrm{~nm}$ nitrocellulose filters and retained for further extraction.

Extracts containing indoles were made from the cell-free culture supernatant and fluid was extracted three times with ethyl acetate after adjusting the $\mathrm{pH}$ to 2.8 and then evaporated at $40^{\circ} \mathrm{C}$ for 20 min. The material was solubilized in sterile distilled water for use in the experiments.

Extracellular proteins were extracted from CaSUT007 culture supernatant by acidifying the fluid to $\mathrm{pH} 2.0$ with concentrated $\mathrm{HCl}$ and allowing the formation of a precipitate at $4^{\circ} \mathrm{C}$ overnight. The precipitate was collected by centrifugation $\left(12,000 \mathrm{rpm}, 4^{\circ} \mathrm{C}, 15\right.$ min), washed three times with distilled water, and dried by vacuum lyophilization. The dried extracellular protein was extracted three times with $100 \%$ methanol for $3 \mathrm{~h}$. The methanol was removed with a rotary evaporator under reduced pressure, yielding a browncolored crude extracellular protein extract. The extract was solubilized in sterile distilled water prior to use in experiments.

\section{Plant bioassays for growth promotion}

The experiment was conducted to evaluate CaSUT007 culture fluid extracts for effects on cassava growth. Stakes of cassava cv. Kasetsart50 were surface disinfested by treatment with $95 \%$ ethanol for $2 \mathrm{~min}$, followed by soaking in $20 \%(\mathrm{v} / \mathrm{v})$ solution of commercial bleach for $20 \mathrm{~min}$. The stakes were then washed with sterile distilled water 5 times in order to remove the bleach. Before planting, cassava stakes were dipped thoroughly in a CaSUT007 liquid treatment. The treatments included a whole culture of CASUT007 in NGB and cell-free fluid from a CASUT007 culture in NGB. Sterile distilled water was used as the control. Cell concentrations in the whole culture were adjusted with sterile distilled water to $1 \times 10^{8} \mathrm{cfu} \mathrm{\textrm {mL } ^ { - 1 }}$, based on absorbance. Other treatments included extracts of extracellular proteins $\left(250 \mu \mathrm{g} \mathrm{mL}^{-1}\right)$ and indoles $\left(50 \mathrm{\mu g} \mathrm{mL}^{-1}\right)$ extracted from CaSUT007. Distilled water was used to dilute the raw extracts to these concentrations, which roughly correspond to those found in NGB cultures with $1 \times 10^{8} \mathrm{cfu}$ CaSUT007 $\mathrm{mL}^{-1}$. In the experiments conducted under greenhouse condition, treated stakes were planted in pots $(30 \mathrm{~cm}$ diameter $)$ containing soils from the cassava field in Nakhon Ratchasima province, Thailand. There were 10 replicate pots per treatment with one stake per pot. The pots were watered daily with water and kept in a greenhouse with a 12-h photoperiod. At 14 days after cassava stakeling emergence, stakelings were harvested for measurements of root and shoot lengths, along with fresh and dry weights. The experiment was conducted two times.

Data from each experiment was subjected to analysis of variance using SAS version 9.1. Separation of treatment means was accomplished by Duncan's Multiple Range Test, and all tests for significance were conducted at $\mathrm{P} \leq 0.05$.

\section{Analysis of indoles}

Supernatants from two types of cultures of CaSUT007 were extracted and assayed for indoles. In one, CaSUT007 was grown in NGB for 12, 48 and $96 \mathrm{~h}$. The indole extract was extracted from cell-free culture supernatants as described above. Indole concentrations were determined based on the method described by Patten and Glick (2002) with slight modifications. For the colorimetric Salkowski assay for indoles, $1 \mathrm{~mL}$ of culture fluid was mixed with $4 \mathrm{~mL}$ of Salkowski reagent and incubated at room temperature for $20 \mathrm{~min}$. The absorbance was measured at $535 \mathrm{~nm}$ using a spectrophotometer (Crozier et al., 1988). The quantity of indoles was determined by comparison with a standard curve using 


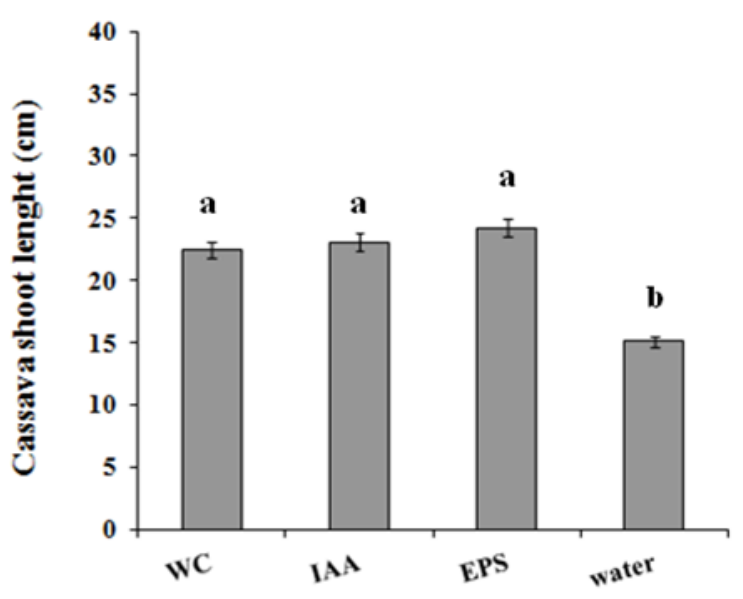

Treatments

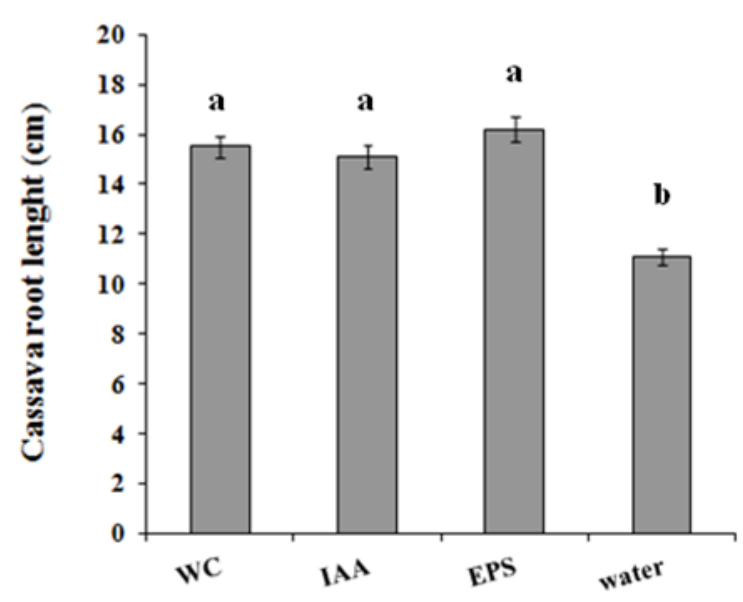

Treatments

A

B

Figure 1. Effects of $48 \mathrm{~h}$ cellular fractions and extracellular extracts from cultures of Bacillus sp. CaSUT007 on the growth of cassava under greenhouse conditions, as measured at 21 days after induction in: A) shoot length; B) root length. WC CaSUT007 = whole culture of CaSUT007; IAA = indole extracted; EPS = extracellular proteins extracted. The data are the average of four replications (three plants per replication) for each treatment. Error bars represent the standard deviation. For each growth parameter, different letters indicate significant differenced $(P \leq 0.05)$ among treatments.

purified IAA in the concentration range of 0 to $50 \mu \mathrm{g} \mathrm{mL}^{-1}$.

\section{Analysis of peptides}

A lipopeptide-enriched extract was obtained from $20 \mathrm{~mL}$ of the crude peptide extract from cultures of CaSUT007 in NGB by purification on an ISOLUTE C-18 CE type cartridge following a modification of the method described by Jacques et al. (1999) and Araujo et al. (2005). The enriched extract was dissolved in butanol and loaded onto a column of a reverse-phase HPLC system. The system was operated at a flow rate of $2.0 \mathrm{~mL} \mathrm{~min}^{-1}$ with $90 \%$ methanol as the mobile phase. HPLC spectra were detected by a UV monitor at $210 \mathrm{~nm}$. The presence of surfactin-type lipopeptides was determined on the basis of retention times compared with those of purified surfactin standards (Sigma S3523).

\section{RESULTS}

\section{Effects of CaSUT007 extracellular factors on plant growth}

Crude extracellular proteins, and indole extracts from cultures of strain CaSUT007 were effective in promoting the growth of cassava under greenhouse conditions. These culture extracts, when applied to cassava stakes, increased root and shoot lengths, by more than $30 \%$ (Figure 1), and increased fresh and dry weights by more than $25 \%$ (data not shown) compared to the distilled water as negative control. Treatment with the extracellular proteins, and indole extracts had similar effects on cassava growth as stake treatments with a whole culture of CaSUT007 (Figure 1). There was signi-ficant effect of cassava stake treatment with CaSUT007 and its products compared with distilled water for any cassava plant growth parameter (Figure 1). Similar results were obtained when the experiment was repeated.

\section{Indole-3-acetic acid analysis}

Strain CaSUT007 secreted IAA as the major auxin, as determined by Salkowski assay, when cultured in NGB medium, with the highest IAA concentration $\left(31.0 \mu \mathrm{g} \mathrm{mL}^{-1}\right)$ detected at stationary phase at $48 \mathrm{~h}$ (Figure 2).

\section{Extracellular proteins as a peptide production}

When the extracellular proteins extract from the culture fluid of CaSUT007 was analyzed by HPLC, high concentrations of bioactive non-polar antibiotics were detected (Figure 3). Surfactin-type peptides were identified in the extract on the basis of their retention times being similar to those of purified surfactin standards, such as surfactin produced by Bacillus sp. ATCC21332. C18 homologues represented together more than $50 \%$ of the total amount of peptides present in the extract.

Based on HPLC peak areas of the peptide extract compared with values obtained for standards, the total amount of surfactins produced by strain CASUT007 


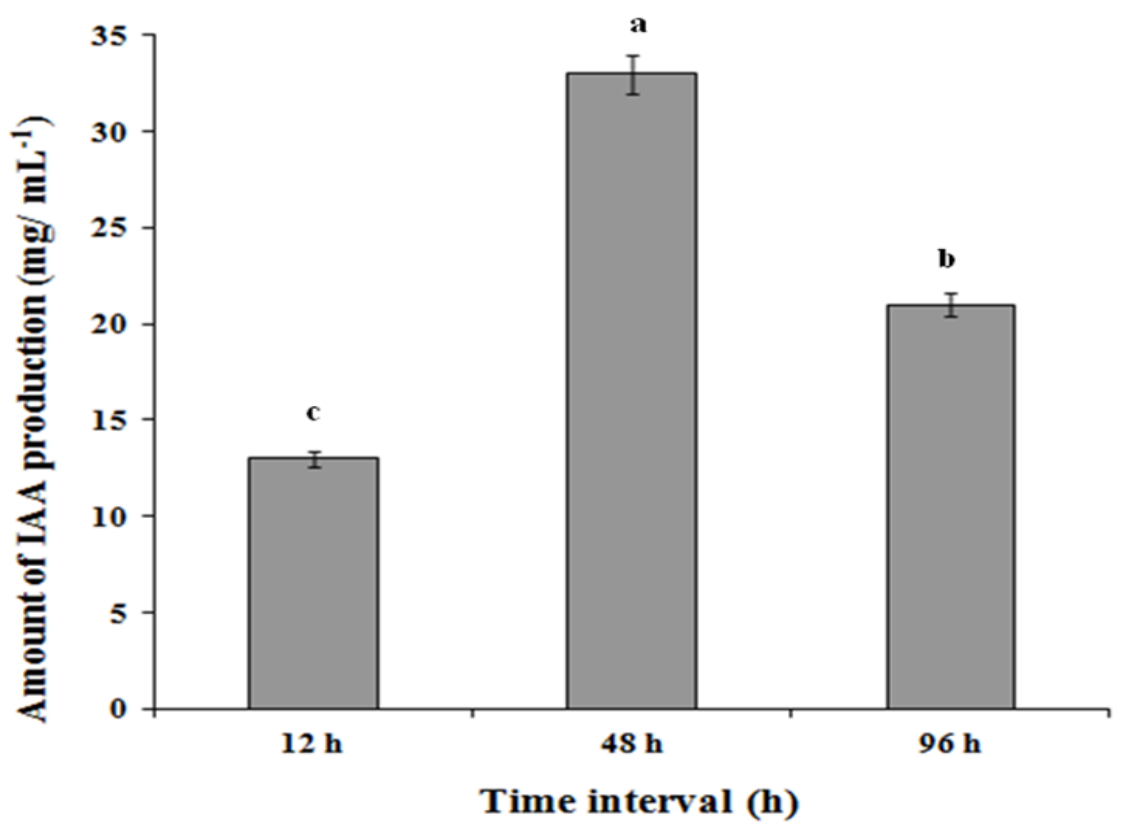

Figure 2. Concentrations of indole-3-acetic acid secreted by Bacillus sp. CaSUT007 grown in NGB medium at difference time interval. The concentration values were standardized to $10^{8} \mathrm{cfu} \mathrm{\textrm {mL } ^ { - 1 }}$ of cells in the medium. The data are the means and standard deviations of three replicates. Error bars represent the standard deviation. Bars with the same letter are not significantly different $(P$ $\leq 0.05)$.

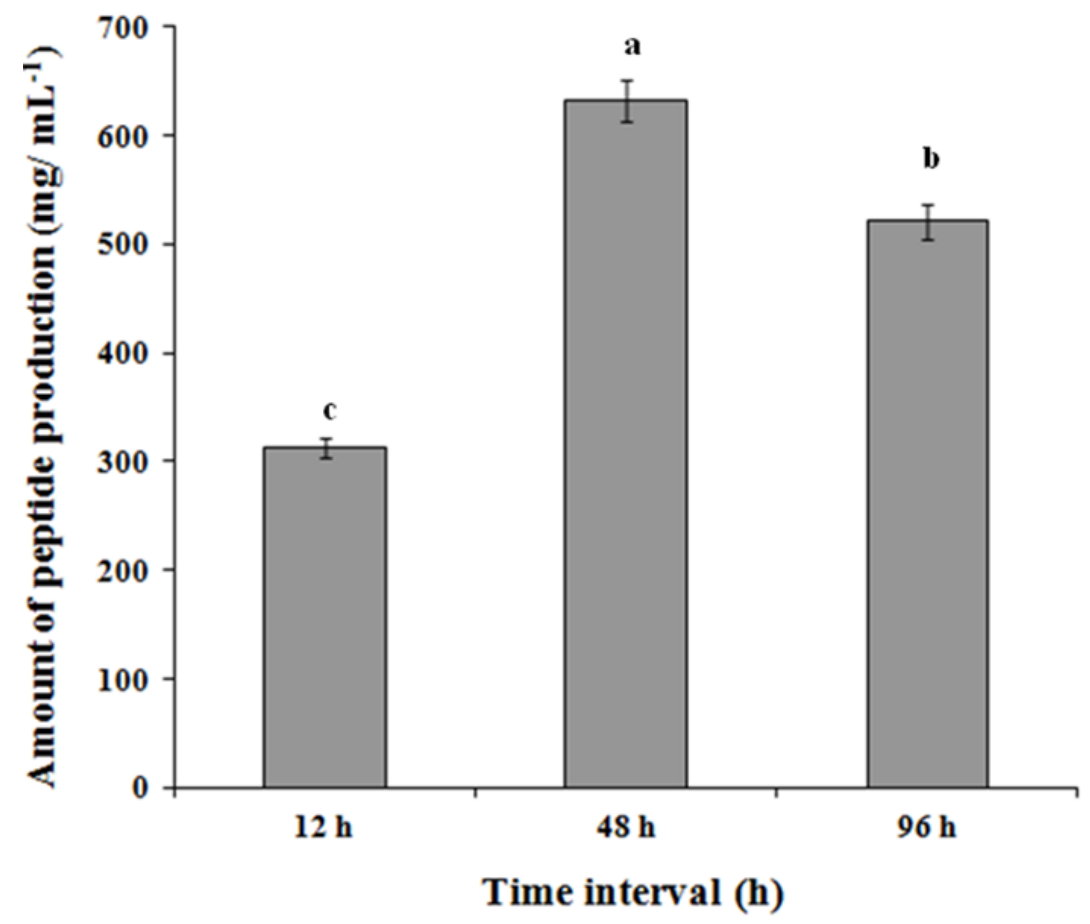

Figure 3. Amounts of peptide secreted by Bacillus sp. CaSUT007 grown in NGB medium at difference time interval. The concentration values were standardized to $10^{8} \mathrm{cfu} \mathrm{\textrm {mL } ^ { - 1 }}$ of cells in the medium. The data are the means and standard deviations of three replicates. Error bars represent the standard deviation. Bars with the same letter are not significantly different $(P \leq 0.05)$. 
was $570 \pm 7.267 \mathrm{mg} \mathrm{L}^{-1}$ at $48 \mathrm{~h}$ (mean and standard deviation calculated from three independent cultures).

\section{DISCUSSION}

This study represents the analysis of metabolite production by Bacillus sp. CaSUT007 in relations to cassava growth promotion. We found that CaSUT007 culture fluid extracts containing secreted indoles, and extracellular proteins individually can influence the growth of cassava to similar degree as cells of CaSUT007 washed free of preformed exoproducts. Whether or not the same type of compounds are secreted by CaSUT007 cells while existing in the rhizosphere remains to be determined, but nevertheless, the results are consistent with the hypothesis that strain CaSUT007 promotes the growth of cassava by secretion of several types of biocompounds.

Based on the fact that each of the crude extracts affected cassava growth and development under greenhouse condition, we surmise that components within each extract had direct effects on cassava, perhaps acting as signaling compounds. Because IAA was the predominant component in the indole extract and its role in plant growth stimulation by plant growth promoting bacteria has been well established (Kutschera and Briggs, 1987; Lambrecht et al., 2000; Patten and Glick, 2002; Martinez-Morales et al., 2003; Araujo et al., 2005; Idriss et al., 2002; Spaepen et al., 2007; Buensanteai et al., 2008), it was most likely that it is the compound responsible for the activity of that extract. The effects of the indole extract on root development apparent in the experiments are consistent with the effects of exogenous IAA. The peak concentrations of IAA detected in the indole extract of CaSUT007 were higher than that reported for any other strains of plant growth promoting bacteria (Araujo et al., 2005; Leveau and Lindow, 2005; Kang et al., 2006). Although small peptide was a major component of the peptide extract, its role in causing the growth promotional effects of that extract was confirmed. If purified small peptide proves to have this effect, then this would be a new function for a secondary metabolite that is better known for its effects on plant cell division (Jacques et al., 1999; Bonmatin et al., 2003; Ongena et al., 2007). There is evidence that certain extracellular proteins can stimulate plant growth by synergizing plant growth action, activating certain plant enzyme systems, or affecting plant cell elongation or division, thereby increasing water or nutrient uptake or excretion of plant factors such as riboflavin (Ernst et al., 1971). But other than a report that extracellular proteins can enhance growth promotion in soybean (Buensanteai et al., 2008), there is precedence for extracellular proteins having a direct effect on plants leading to elevated growth (Vessey, 2003). This study represents the first analysis of the extracellular proteome of a Bacillus species in relations to cassava growth enhance- ment (Zavahir and Seneviratne, 2007).

Ultimately, the approaches used in this study could increase understanding of the modes of action by which Bacillus sp. CaSUT007 enhances cassava growth. With such information, we could potentially enhance the efficacy of CaSUT007 strains or better exploit such strains as sources of new bio-products in the near future.

\section{ACKNOWLEDGEMENTS}

This work was supported by the Suranaree University of Technology and by the Higher Education Research Promotion and National Research University Project of Thailand, Office of the Higher Education Commission. Also, this research is partial support by funds from the Thailand Research Funds MRG558. The first author wishes to express special thanks to the France Embassy for the Junior Research Fellowship Program 2011. Moreover, thanks goes to the European Community Mobility Programme Erasmus Mundus, Parnerships Action2 (EMA2) and European Academic Mobility Network with Asia for the EURASIA2 funding support.

\section{REFERENCES}

Araujo FF, Henning AA, Hungria M (2005). Phytohormones and antibiotics produced by Bacillus sp. and their effects on seed pathogenic fungi and on soybean root development. World $\mathrm{J}$. Microbiol. Biotech. 21:1639-1645.

Bonmatin JM, Leprevote O, Peypoux F (2003). Diversity among microbial cyclic lipopeptides: Inturins and surfactins: Activitystructural relationships to design new bioactive agents. Comb. Chem. High Throughout Screen 6: 541-556.

Buensanteai N, Thumanu K, Sompong M, Athinuwat D, Prathuangwong $S$ (2011). The FTIR spectroscopy investigation of the cellular components of cassava after sensitization with plant growth promoting rhizobacteria, Bacillus subtilis CaSUT007. Afr. J. Microbiol. Res. 6(3): 603-610.

Buensanteai N, Yuen GY, Prathuangwong S (2008) The biocontrol bacterium Bacillus amyloliquefaciens KPS46 produces auxin, surfactin and extracellular proteins for enhanced growth of soybean plant. Thai J. Agric. Sci. 41 (3-4):101-116.

Crozier A, Arruda P, Jasmim JM, Monteiro AM, Sandberg G (1988) Analysis of indole-3-acetic acid and related indoles in culture medium from Azospirillum lipoferum and Azospirillum brasilense. Appl. Environ. Microbiol. 54:2833-2837.

Ernst R, Arditti J, Healey PL (1971). Biological effects of surfactants: I. Influence on the growth of orchid seedlings. New Phytologist 70:457475.

Idriss EE, Makarewicz O, Farouk A, Rosner K, Greiner R, Bochow H, Richter T, Borriss R (2002). Extracellular phytase activity of Bacillus amyloliquefaciens FZB45 contributes to its plant-growth-promoting effect. Microbiol, 148: 2097-2109.

Jacques P, Hbid C, Destain J, Razafindralambo H, Paquot M, De Pauw E, Thonart $P$ (1999). Optimization of biosurfactant lipopeptide production from Bacillus sp. S499 by Plackett-Burman design. Appl. Biochem. Biotech. 77: 223-233.

Kang BR, Yang KY, Cho BH, Han TH, Kim IS, Lee MC, Anderson AJ, Kim YC (2006). Production of indole-3-acetic acid in the plantbeneficial strain Pseudomonas chlororaphis $\mathrm{O} 6$ is negatively regulated by the global sensor kinase GacS. Curr. Microbiol. 52: 473476.

Kloepper JW, Ryu CM, Zhang S, (2004). Induced systemic resistance 
and promotion of plant growth by Bacillus spp. Phytopathol. 94:12591266.

Kutschera U, Briggs WR (1987). Rapid auxin-induced stimulation of cell wall synthesis in pea internodes. PNAS 84: 2747-2751.

Lambrecht M, Okon Y, Broek AV, Vanderleyden J (2000). Indole-3acetic acid; a reciprocal signaling molecule in bacteria-plant interactions. Science 8:298-300.

Leveau JH, Lindow SE (2005). Utilization of the plant hormone indole-3acetic acid for growth by Pseudomonas putida strain 1290. Appl. Environ. Microbiol. 71:2365-2371.

Martinez-Morales LJ, Soto-Urzua L, Baca BE, Sanchez-Ahedo JA (2003). Indole-3-butyric acid (IBA) production in culture medium by wild strain Azospirillum brasilense. FEMS Microbiol. Lett. 228:167173.

Ongena M, Jourdan E, Adam A, Paquot M, Brans A, Joris B, Arpigny JL, Thonart $P$ (2007). Surfactin and fengycin lipopeptides of Bacillus subtillis as elicitors of induced systemic resistance in plants. Environ. Microbiol. 9:1084-1090.
Patten CL, Glick BR (2002). Role of Pseudomonas putida indole acetic acid in development of the host plant root system. Appl. Environ. Microbiol. 68:3795-3801.

Spaepen S, Vanderleyden J, Remans R. (2007). Indole-3-acetic acid in microbial and microorganism-plantsignaling. FEMS Microbiol. Rev. 31:425-448.

Vessey JK (2003). Plant growth promoting rhizobacteria as biofertilizers. Plant Soil 255: 571-586.

Zavahir JS, Seneviratne G (2007). Potential of developed microbial biofilms in generating bioactive compounds. Res. J. Microbiol. 2: $397-$ 401. 